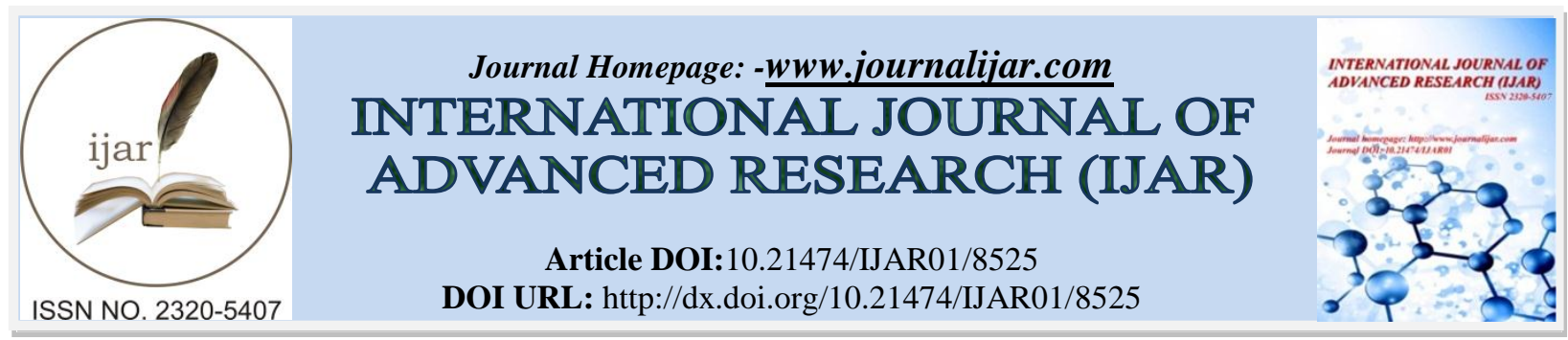

RESEARCH ARTICLE

\title{
AN ETHNOGRAPHIC DESCRIPTION OF LIFE-STYLES, CULTURE AND NEWLY EMERGED MULTIPLE DIMENSIONS OF INDIAN MIDDLE CLASS IN AN URBAN SETTING OF KOLKATA, WEST BENGAL.
}

Debasree Chowdhury.

Research Fellow (UGC/NET), Department of Anthropology, University of Calcutta, 35 Ballygunge Circular Road, Kolkata - 700019, West Bengal, India.

\section{Manuscript Info}

\section{Manuscript History}

Received: 06 December 2018

Final Accepted: 08 January 2019

Published: February 2019

Key words:-

Transnationalism, new Indian middle

class, GIC (glocalized intermediary

class), popular images, consuming culture.

\begin{abstract}
The purpose of this research is to understand the 'new Indian middle class', as a class of life-styles and cultures of consumption and specific forms of capital under current neoliberal globalizing regime. This ethnographic endeavor particularly uses semi-structured and depthinterviews of purposively selected 7 (no. of) young professionals working in the constellations of multi and trans-national companies in New Town, Rajarhat, Kolkata and West Bengal. The interpretive study provides the thematic analysis of the competing 'capitals' in their lived 'fields' of education, work, identity enactments and consumption. The foci of the analysis emergent from the qualitative data are their educational fields, fields of self-care, practicing criteria of preference for certain employments, fields of consumption, assessments of the fields of securing social status or prestige, fields of negotiation with the traditions in their social life, and enacted social spaces to which they think to belong.
\end{abstract}

Copy Right, IJAR, 2019,. All rights reserved.

\section{Introduction:-}

Since 1991, with the policy of economic liberalization began in earnest, the size and successfulness of India's middle class have grown considerably. Sociologists of the west usually distinguish between the 'old' middle class the property-owning petty Bourgeoisie and the 'new' middle class of educated and qualified, professional and technical, white-collar staff, which have grown steadily since the nineteenth century (Giddens 1973: 177-9). In India, this new middle class was a product of colonial rule and, even though very influential, it remained tiny compared with its western equivalent until recently (B'eteille 2003a: 76-9; 2003b: 192-4). Proportionally the Indian middle classes make less than a quarter of the total Indian population, whereas its absolute size is larger than the population of many countries of the world, which by itself renders a wide consumer base to a market-based economy. It is intimately connected to India's explosive, urban growth brought on by globalizing policies of economic liberalization. One of the important features of the Indian middle-class is its internal diversities of income, occupation, caste, community and region. While the New Indian Middle Classes are mobile globally, acting locally, consume spaces (rather than inhabit places) and use the language shifting from local to global contexts.

They also actively participate in identity politics more inclined to 'global' senses. Such a flexible articulation of life allows transformations of bodily practices, such as the creation of leisure spaces, fashionable consumption, more 
dwelling space, national and international employment, mobility and independence more as consumers than workers. India's new middle class attaches a multitude of traditions, global-local social interface and political configurations. This is surely good news for the global economy in general and for the Asian economy in particular, as most of the expansion in the global middle class comes from Asia. Although discerning that the middle class is as much a social designation as an economic categorization, most economists choose to measure it in terms of income or consumption levels. India's growth accomplishments since the 1990s have put the living standards of many Indians under global scrutiny. While the economic literature has primarily focused on poverty and inequality, the chances of the "new Indian middle class" have received substantial attention in the media and business journals, as their earning voltage and spending habits have important implications for the national/global economy.

\section{Objective:-}

Understand the new Indian middle class/es ethnographically as class, culture and in-between. The focus is to define the new Indian middle class, such as to identify and describe the phenomenon in detail.

\section{Methodology:-}

The discussion, however, which is based on data collected in Kolkata (formerly Rajarhat; IT sector), looks at one of the most high-profile sections of the new-rich middle class in urban India; the professional staff in the new information technology (IT) companies that furnish 'the indispensable, material basis' for the 'informational global' economy. This section contains ethnographic sketches of some of the people working in IT whom I have interviewed. The research methodology was purely qualitative in nature. Methods like, interview (unstructured and/or semi-structured, open-ended and in-depth), observation (mainly, participant observation) have been employed.

Table no 01:-represents some basic information's about the informant's.

\begin{tabular}{|c|c|c|c|c|}
\hline $\begin{array}{c}\text { Fictive name of the } \\
\text { informant }\end{array}$ & Age in years & Sex & $\begin{array}{c}\text { Educational } \\
\text { Qualification }\end{array}$ & Profession \\
\hline Toton & 25 & Male & B.Tech & Educator \\
\hline Jeet & 34 & Male & B.A & System Analyst \\
\hline Prodip & 28 & Male & B.Tech & Software Engineer \\
\hline Mr. Roy & 40 & Male & MBA & $\begin{array}{c}\text { Project manager or } \\
\text { leader }\end{array}$ \\
\hline Mr.Tiwari & 30 & Male & M.Tech & Software Engineer \\
\hline Ms. Sen & 29 & Female & B.Tech & $\begin{array}{c}\text { Technical } \\
\text { Consultant }\end{array}$ \\
\hline Mr. Kumar & 30 & Male & M.Tech & Software Engineer \\
\hline
\end{tabular}

\section{Defining the new Indian middle class:}

The middle class can be defined in relative or absolute terms. In studies of this increasingly prominent stratum in various Asian countries, as well as India, 'new rich' is the deliberately loose phrase chosen to emphasize that it is indeed new and rich, as well as to evade some definitional difficulties surrounding 'middle class' (Pinches 1999; Robison and Goodman 1996). Delimited in this way, the global middle class excludes those who are conceived poor in the poorest developing countries and those who are considered rich in the richest advanced country. Education is perceived to be the main resource for the middle class to generate economic capital (money and assets such as real estate), social capital (status and knowing the right people) and cultural capital (credentials and habitus of the middle class as distinct from the poorer, uneducated masses and from the rich, often business, elite). Following Bourdieu`s "Social Critique of the Judgment of Taste" it is characteristic for intermediate classes to show behavior of distinction towards the ones below them in the social ladder and simultaneously to display a sense of "pretension" (or imitation) towards the classes above them (Bourdieu1984). This potentially covers a very large and varied group of individuals; but the Indian middle class has been typically comprehended to be an educated segment of urban society employed in or seeking white collar jobs. The new middle class in India has distinguished some 'unexampled' aspects of the middle class in the following ways. 


\section{Education serves as cultural capital}

Education was the main resource for the middle class. It could be converted into economic capital, social capital (status) and cultural capital (credentials and habitus) (Bourdieu 1984). Thus, for the elites and the middle classes cultural capital was more easily convertible to economic capital through advanced academic credentials, or by helping them face interviews or secure loans. Private English-medium education as a key marker of middleclassness, but also as a site of cultural capital, where cash is spent to expose children to the culture of the dominant, changing their very habitus (Bourdieu 1984; Jeffrey et al. 2004; Osella \& Osella 2000), has become more widely available to a growing number of middle-class newcomers. Nowadays increasingly in an urban population, who are more likely than others to have the social skills and cultural knowledge, including fluency in English, needed to work with global IT companies and to pass their selection tests in the first place. In the early 1990s, B'eteille analyzed the role of the family and education in reproducing class inequality, observing that middle-class parents 'take an increasingly active part in their [children's] education and training. [They] have become increasingly career conscious, and this consciousness is implanted in their children at a young age' (1991:17). This is still truer today and even more than in the 1970s, when Lionel Caplan studied attitudes towards education among middleclass Christians in Chennai (1987: 62-6) all middle-class children, encouraged and pressurized by their parents, know that they must strive to gain the best possible examination marks.

Giddens defines structure as "the rules and resources recursively implicated in their production of social systems" (Giddens, 1986, p. 377). Rules are the patterns of social life. Resources are the means through which power is exercised in these patterns. Structure enables and constrains social action, but structure is something created and used by actors, not an external reality, a "thing," used on, for, or against actors. Structure can be transformed or reaffirmed as actors use its rules and resources in real, concrete social situations. It is transformative and flexible and depends upon the "regularities of social reproduction" (Giddens \& Pierson, 1998, p. 77). In his analysis of French schools (as a particular field of play), In turn, 'imbued with the cultural capital recognized, examined and rewarded within schools, and drawing also on their wealth and social contacts, the upper and middle class are typically able to manipulate the education system so as to reproduce their advantage in the next generation' (Jeffrey \& McDowell 2004). Nevertheless, they have a real impact, so it affects how strongly children are socialized into their educationoriented career consciousness. Toton mentioned,

"From our childhood we know that we must secure exceptionally high examination marks to get into the best engineering and other professional colleges, where many seats are reserved. Because MNCs are allows only candidates with consistently high marks to apply for posts, its selection policy in practice favors those candidates who, from a tender age, have been motivated to achieve repeated scholastic success."

For this Bourdieu developed the concept of 'cultural capital' - the symbolic credit which one acquires through embodying and enacting signs of social standing. This social resource, analogous to and complexly intertwined with economic and social capital, derives from three sources: certain material possessions, institutional recognition (e.g. in the form of education credentials), and certain styles of behavior and competences, such as 'intelligence' and 'taste', or the mastery of a language (Bourdieu 1986). He stressed that these types of capital must be understood according to his concept of 'fields' of play. Bourdieu viewed society as an ensemble of relatively autonomous fields (e.g. class or school education) of social competition where agents' positions vary according to their possession of a combination of varying amount and weight of cultural, social, and economic capital (Bourdieu 1984). Higher socioeconomic background makes time of cultural acquisition in schools and has a great impact on the cultural capital that can be accumulated throughout a lifetime; which plays as a filtration in the reproductive process of hierarchical society. Cultural capital is converted into economic capital and also vice-versa.

\section{Consumerism}

The emergence of a consumer-based identity the new Indian middle class emphasizes the rights of the consumer citizen rather than the rights of the worker (Sarkar 2008). There is some envious distaste for the IT professionals' high salaries and alleged preoccupation with money, for salaries in other industry are generally lower, and promotion and increments come more slowly. IT professionals themselves readily acknowledge that high salaries matters a lot. Expenditure on prestigious housing and education is, of course, ostentatious consumption, as well as generally sound investment. Mr. Roy stated,

"The money means that I can now enjoy a very comfortable standard of living comparable with that available in the west. New forms of consumer expenditure notably holidays, both in India and abroad are becoming common in my 
life, although most of the income is spent on purchasing the apartment, its decoration and maintenance; for the children, costly private education is also a major expense."

Software companies at Rajarhat in Kolkata have dress codes, such as 'business formals' on Monday, 'business casuals' from Tuesday to Thursday, and 'casuals' on Friday and at weekends. On all days, however, a large majority of female IT professionals wear a tee-shirt and jeans, although some wear a sari or a 'western' blouse and trousers on formal days. No women in are scruffily dressed, but I was struck by the modest and even unfashionable clothes worn by some of them. Writing about the newly emerging middle class of Kathmandu, Mark Liechty emphasises "the constantly contested, highly materialistic, and anxious character" of their lives (2002: 18) and the "precarious and fleeting" nature of middle-class status (ibid. 19), and he also argues that "commodities . . are the primary currency of middle-class life" (ibid. 31). For IT professionals, as members of the new-rich, middle class in Chennai, consumption especially in housing and children's education obviously is important for their class status (Lakha 1999).

Although structures exist only through human action and can, therefore, be changed by that action, they remain relatively stable because people continue to reproduce them and thus have a self-preserving bias. For example, as citizens in a consumer culture, we continue to place value on material goods beyond their use value, we continue to buy and reproduce the structure that determines that we need new things (e.g. better things, more things) than are necessary for survival or even a modest level of comfort. As agents/consumers we buy and perpetuate the structure of consumer culture. The compliance of agents is necessary for structures to be produced, reproduced, and transformed. However, agents are not aware that their actions involve structures due to the resources agents have access to and the rules they are bound by in everyday life situations. Agents then compete to gain control over the species of capital that are most effective and hold a high value in the particular field of play, which in turn provides each field's own internal logic and regulatory principles that govern the game on the field. Therefore, people with the right combination and volume of capital resources and with a habitus - 'internalized orientations to action inscribed in people's demeanor reflexes and tastes that both reflect people's histories and shape their futures' (Jeffrey 2010: 19) that match a particular field will outmaneuver people who lack the resources and attuned habitus.

In a slightly more understandable definition than Giddens's own, J. H. Turner (1991) says, "Structuration is, therefore, the dual processes [structure and agency] in which rules and resources are used to organize interaction across time and in space and, by virtue of this use, to reproduce or transform these rules and resources" (p. 526-527). Specifically, structuration is the process whereby social relations and individual actions create structures that remain relatively stable across time and space. Structures are neither solidified nor stable; instead, structures are perpetuated to appear so by the continued taking of action (Giddens \& Pierson, 1998). Structure is created, maintained, and transformed through the actions of agents or the agency of human actors. Without structure, agents would have no meaningful context for actions, and without actions, structure would not be formed and perpetuated. This is the "duality of structure," the core of how structuration comes about. Agents act and these actions produce social systems, while social systems allow and constrain agents' actions. This process of mutual influence between structure and agency is continuous and simultaneous.

This contrasts with the situation of the white-collar workers in Mumbai discussed by Leela Fernandes, who belong to a rather lower segment of the middle class and face much uncertainty owing to the restructuring of the city's labour market. Among these people, a contradiction exists between economic uncertainty and their 'aspirations' towards 'prosperity and consumption that characterize images of the "new" middle class dream in liberalizing India' (Fernandes 2000: 103). The finding of my study shows that most of the IT professionals have to deal with this contradiction, which is probably one main reason why most of them appear anxiously preoccupied by consumption as a signifier of status. "Consumption becomes a symbolic act signaling 'modernity' and membership in the ascriptive category 'middle class'" (Gehrke 2000: 145).Toton mentioned,

"I like to buy new things especially new gadgets. Brand is important for its quality and also durability. I am very much selective person. We know that shopping or buying new things gives mental pleasure. Basically I like to buy online; it is more hazards free and simultaneously it gives more option to choose."

Earning in local comparison relatively high salaries they "find themselves with the purchasing power to consume goods and services that affirm and validate the identities they construct for themselves: for instance by drinking coffee at Starbucks" (Fabros 2007: 250). Younger middle-class people in Kolkata are notably less preoccupied than 
their elders have been with saving for the future and less willing to wait to buy property and consumer goods. Often using loans, young professionals buy apartments or houses much earlier than their parents did, so that people even say that housing now comes before children, which it never did in the past. Prodip contrasted his own spending pattern with his father's,

"I live in and for the present, my father cared too much about our future. Yes, I have also future plan like others through savings. But generally, I consult with my father before taking any decision on this matter. Recently we have renovated our home. Though, very soon I would shift to another place in Kolkata. I'll buy an apartment at Rajarhat after marriage."

"Today's mantra is live for the present. I also try to maintain this. Nowadays, I become a very calm person. I just don't want to think too much. Whatever I lost in my life, I believe that was my fate. Today I have lost my health for my over thinking habit."

\section{Private sector employment}

Whereas jobs used to offer security in the context of a long-term career with steady promotion prospects and a stable managerial structure, as is still largely true in IT sector also. Linked to the younger generation's confidence is total disdain for government and public-sector employment. Deshpande argues that the managerial-professional middle class formerly identified with Nehruvian development and, as globalization has displaced it, any commitment to the Indian nation has faded away (2003: 150). Whereas till late 1990s, the state sector has been encouraging early retirement and recruiting new personnel at a very low rate. Nevertheless, much more salient is the assumption that low salaries, bureaucratic hierarchies an stifling conservatism characterize these jobs, and given their sense of economic and occupational security, younger people see no point in 'safe' employment with the state ( Fernandes 2000: 92). As it would have been increasingly unchallenging and monotonous profession. Every informant's disdain for government and public-sector employment raises the question of their attitude to the Indian nation state. Interestingly, some informants did speak negatively about public-sector employment. Many informants mentioned that the government has become corrupt and no longer serves the nation and people. They possess less interest in this sector. Mr. Tiwari summed it up well,

“Earlier people worked to achieve 'benchmarks', government jobs were preferred, and a 'monthly salary was looked upon as a great thing', whereas it no longer exist. Nowadays, who used to work in IT are mainly young people; they change jobs in 'every two years' and move up the ladder each time. In present condition, government jobs were the route to a 'settled life', but now they pay relatively badly, today's 'working culture' is more impatient and nobody just wants to 'count their yearly increment'."

In IT companies like IBM, INFOSYS and TCS, the staffs who do well, can expect rapid promotion and salary increases. Managerial hierarchies are deader in IT companies than in other industries, which are more like the bureaucratic hierarchies of government and public-sector organizations with systems of promotion by seniority and age-related salary scales. Moving between companies, especially in junior and middle management grades, is fairly common in every sector. In the IT sector, too, people constantly talk about moving and they can change jobs quite easily if they want to, so that all IT firms are very concerned about 'attrition rates' and retention of high-quality staff. Among their peers, some of them are repeatedly moving between firms primarily for career and financial advancement. Among them, whether they have been changing jobs or not, levels of career-minded ambition are variable. Prodip commented,

"TCS is my fourth company. I want money; where I can get better salary structure I always ready to move. But specifically IBM has different work culture; they have different structure, the career scope quite high. I miss their culture, those environments. Sometime I regret for my decision."

Software engineering does not demand exceptional ability, as some experienced people acknowledge; but I have met several IT professionals who are bored because their work is too easy, and it is widely recognized that seriously ambitious people might have to move into new fields; for example, by taking an MBA degree so that they can apply for a range of top managerial positions; or, they might fulfill their dream project. They talk about it as a possibility and about the limitations of a career as a software engineer. Quite a lot of people, though, are not especially ambitious; for example, two informants do not want to go abroad again, which will probably slow his future advancement. Prodip assured, 
"Now, I don't want to go abroad. Because recently I'll be marry. And I want to establish my future here."

Toton also said,

"No, I don't have any shifting plan for abroad. For career improvement I just think to get MBA degree. But it takes some time."

And one man expressed his desire to move to a 'low pressure' job eventually. Prodip shared,

"Actually from my childhood I grow up with a dream to become a film director. Eventually I save money to fulfill my dream. After accumulating a lot of money I would like to retire from my job. No longer have I just wanted to be a tech labor."

Attitudes, moreover, are gendered. Although some women in the IT industry do refer to their sense of empowerment, career ambitiousness is certainly common among men than women. One of the main reasons is that why young people are unimpressed by safe monthly salaries and annual increments because they just do not fear for unemployment and poverty like many of their parents did at their similar age. Prodip told,

"You know very well that after passing I waited for a long time. I have a great faith and confidence for myself. If you feel unconfident you'll definitely lose yourself."

Nonetheless, it is also widely believed, especially but not only by young people, that the Indian IT industry as well as profitable companies in manufacturing industry has a bright, long-term future in an environment of irreversible economic liberalization and globalization. Hence workers in these industries can be confident about their own futures, even if they must sometimes change or even lose their jobs during recessions. Within India, this optimism is probably confined to people working in the most expansive sectors of the economy, who do not include 'restructured' white collar staff in Mumbai (Fernandes 2000). The younger generation's confidence in the future also means, of course, that they are confident about their middle-class status, unlike the more anxious people studied by Fernandes in Mumbai, Mankekar in Delhi and Liechty in Kathmandu; for example, many young men said that they hoped for a more interesting life than becoming salary men (Vogel 1971: 274). Mr. Roy wished,

"Money is everything and also important for us but sometime I feel myself like a robot. Rest of my life I want to live a target free life; though it's my heartfelt wish I don't know when I'll fulfill it. We're behaving like a machine."

\section{Status or prestige consciousness}

Economic, social, and cultural capitals interact in numerous settings. Onlookers must be compellingly converted and persuaded of one's class identification. In addition, it seems that they also show significant distinction. But for most people in the middle, the performance of class is 'a delicate, fragile thing that can be shattered by very minor mishaps'. Such points highlight how both dignity and class standing are affected by the judgments of a relevant community. 'Dignity' in usage is an acquired or contingent dignity (Meyer 2002: 197; Schaber 2011: 152). It is much more closely related to the intangible qualities of esteem, and especially regard and recognition, that have recently been taken up by a small number of economists and political sociologists (Brennan and Pettit 2004; Castleman 2011; Offer 2006; Sayer 2005). Giddens's use of the term "regionalization" is largely borrowed from Goffman (1959), who states that locales differ in terms of their modes (boundaries - physical and symbolic, duration across time, span in physical space, and character), disclosure of self, and extent of understanding of front stage (public) and back stage (private) performance aspects (Goffman, 1959; J. H. Turner, 1991).

Dignity is not part of the material sources or even the symbolic signs of class that are usually analyzed in class studies; it is closer to affect. In Kolkata, the primary way of articulating this desire for dignity in daily discourse has to do with class more than with any other form of identity. The struggle for dignity emerges among them from their interactions with others and in behaviors that aim to elicit regard from others. Rather people need to feel seen and recognized, to be accorded presence, in order to feel dignity and self-worth (Mines 2005; Sayer 2005). Middle-class people often speak of themselves in Goffmanesque terms, as acting on a stage surrounded by a critical audience (Dickey 2013; Goffman 1959). Giddens (1986) identifies three areas of knowledge that all agents possess: discursive, practical, and unconscious. Social actors are aware of each of this knowledge at different levels. In case of Kolkata's ITs' status or prestige is closely related with consumption. Buying expensive materials gives social value to them (Observed from their gesture, the way of talking, attitude and interaction). 


\section{Consume transnational spaces rather than inhabit}

The New Middle Class are increasingly mobile. In the context of post-liberalization India, the new middle-class identity has been increasingly tied to globalization with regards to the creation of mobile personal and professional identities and discursive transnational spaces (Sarkar 2008). The evidence largely confirms this; all IT professionals strongly support economic liberalisation and India's integration into the global economy (Upadhya 2004), and so too do many other company managers, although enthusiasm is less in businesses that relied on the old regulated economy (Harriss 2003: 339-40). The invention of a "glocalized intermediary class" (GIC) is better to capture the social location of transnational class situation in between societies of the Global North and the Global South. The GICs can be conceived to be portion of the (service or white collar) but at the simultaneously to be portion of the middle class in the society of their origin (in this case: the Kolkata). If the middle class (es) can be interpreted as a "contradictory class position", this is even compounded for GICs working and living in between the worlds and the class positions.

The explorative theory of a "glocalized intermediate class" is represented by the agents working at IT in Kolkata. They are working at transnational working places and can be considered socio-cultural migrants. It can be termed as "transmitting society" and conceive its motto to be the Microsoft slogan "Where do you wish to go now?" This class is economically webbed and ethnically linked (by Internet and cyber society), socially established and secured. These people therefore could be categorized as "global serve class". They have at least one thing in usual; they fulfill, intentionally or unintentionally, the (flexibilized) functional requirements of universal capitalism. Leslie Sklair says "The transnational capitalist class [...] is transnational in at least three senses; its members tend to have global rather than local perspectives [...]; they tend to be people from many countries, more and more of whom begin to consider themselves 'citizens of the world' as well as of their places of birth; and they tend to share similar lifestyles, particularly patterns of luxury consumption of goods and services" (Sklair 1995:71). This/These class/es seem most often only as actors of the "communication society" narrative, which tells the story of a cultural synchronization of world society in form of a universal culture, which is practiced after the western or even American path and suggests or better mocks an unlimited freedom for each and every citizen of this society "to go where s/he wants today". Jeet told,

"If I get better scope outside in India, I'm always ready to shift. Because their work culture as well as pay scale is far better than us. Though, this perception differs individually. Most of the time at our initial professional time period we want to go outside of India. In abroad they ask for only the certificate of technology; nothing else. At there, even you have the chance to work from your home. There is no bullshit of politics like us. You can back with a lot of money."

Social and cultural both capitals are useful in industries involved in cross-border commerce. The experience of living abroad was highly prized. 'Global champions' demonstrate not only adaptability, but also a capacity for cooperation helps in the global economic labor market.

\section{Conclusion:-}

The New Middle Class has great materialistic aspirations. They generally live on a fixed income and on a rigid budget. The former is exemplified by Pavan Varma's The Great Indian Middle Class (1998), which excoriates this class for its selfish materialism and the 'retreat from idealism' that was manifest in the smaller, 'traditional middle class' of the earlier, post-independence period (ibid.: 89). This may especially be true in a newly emerging class for which the material and processual indicators are in great flux. And finally the fact that their income transcends the "necessary" motivates GICs to invest it into conspicuous goods which can be seen as demonstrative consumption. Gehrke considers this to be a "part of the class formation process [as] the production of lifestyle is not just a personal matter; it is also directed towards the establishment of social boundaries and structures of exclusion, in order to establish a 'collective' identity" (Gehrke 2000: 149). The new Indian middle class has been an important historical and sociological category in modern India. In sum, across India the neoliberal reform process has given rise to a new form of class and culture, reflected in not only diverse attitudes towards earning and consuming, women's entry into the emblematic life-style, but also in relation to the spatial restructuring of urban spaces which, in many instances, become sites of class-based, cultural contestation.

They transcended 'being Indian' while 'Indianising' the global, creating momentary figurations what we might call globalization of flux and flexibility. Satish Deshpande claims that the middle class especially its upper, managerialprofessional segment is the principal beneficiary of globalization, and that 'much of the celebratory rhetoric about 
[it] emanates from, and is aimed at, this group' (2003: 150). This class is linked with private sector employment especially, in the growing Information Technology industry. The rise of the new middle class is associated with the spread of Information and Communication technologies (Sarkar 2008). The new entrepreneurs, managers and technocrats in contemporary China and Vietnam probably constitute the plainest examples of the Asian new rich (Robison and Goodman 1996: 3-6). In India, owing to its mixed economy, liberalization had less radical outcomes, but it has also fostered the emergence of a comparable new rich of entrepreneurs and professionals in the private sector. It is commonly asserted that IT professionals are overpaid, greedy, and materialistic and obsessed by dreams of migrating to the west. They are all said to be overworked, too, which drives some of them into depression or even anxiety, although many of them allegedly lead wild lives in bars at late night and have lots of illegitimate affairs as well. In many respects, these stereotypes echo complaints about the newly middle class's materialism and selfishness as set out by Varma (1998).

\section{References:-}

1. B'eteille, Andr'e. (2003): 'The Social Character of the Indian Middle Class.' Middle Class Values in India and Western Europe, Imtiaz Ahmad and Helmut Reifeld, Eds, 73-85. New Delhi: Social Science Press.

2. Béteille, André. (1991): 'The Reproduction of Inequality: Occupation, Caste and Family.'

3. Bourdieu, P. (2011): The forms of capital. (1986). Cultural theory: An anthology, 81-93.

4. Bourdieu, Pierre. (1984): Distinction: A Social Critique of the Judgement of Taste. Translated by Richard Nice. Cambridge: Harvard University Press.

5. Brennan, Geoffrey and Philip Pettit. (2004): The Economy of Esteem: An Essay on Civil and Political Society. Oxford: Oxford University Press.

6. Caplan, Lionel. (1987): Class and Culture in Urban India: Fundamentalism in a Christian Community. Oxford: Clarendon Press.

7. Castleman, Tony. (2011): 'Human Recognition and its Role in Economic Development: A Descriptive Review.' Institute for International Economic Policy Working Paper Series, The George Washington University. Contributions to Indian Sociology (N.S.) 25 (1): 3-28.

8. Deshpande, Satish. (2003): Contemporary India: A Sociological View. New Delhi: Penguin Books. On gaining recognition as middle class in Madurai / 241Contributions to Indian Sociology 47, 2 (2013): 217-243

9. Dickey, S. (2011): The Pleasures and Anxieties of Being in the Middle: Emerging Middle-Class Identities in Urban South India. Mod. Asian Stud. Modern Asian Studies, 46(03), 559-599. doi:10.1017/s0026749x11000333

10. Dickey, S. (2013): "Apprehensions: On Gaining Recognition as Middle Class in Madurai." Contributions to Indian Sociology 47, no. 2: 217-43. DOI: 10.1177/0069966713482963.

11. Edgecomb, E. (2010): Looking Good and Taking Care: Consumer Culture, Identity, and Poor, Minority, Urban Tweens.

12. Fabros, A. (2007): Social production of outsourced selves: A view of call centre regimes and experiences in the Philippines. Master Thesis (unpublished), University of the Philippines: Diliman.

13. Fernandes, Leela. (2000): 'Restructuring the New Middle Class in Liberalizing India.' Comparative Studies of South Asia, Africa and the Middle East 20: 88-111.

14. Fuller, C. J., \& Narasimhan, H. (2006): Information Technology Professionals and the New-Rich Middle Class in Chennai (Madras). Mod. Asian Stud. Modern Asian Studies, 41(01), 121. doi:10.1017/s0026749x05002325

15. Gehrke, S. (2000): Global Lifestyles under Local Conditions: the New Indonesian Middle Class. In Beng-Huat Chua (Ed.), Consumption in Asia: Lifestyles and identities, (pp. 135-158). London: Routledge.

16. Giddens, A. (1986): The constitution of society. Berkeley, CA: University of California Press. (Original work published 1984)

17. Giddens, A., \& Pierson, C. (1998): Conversations with Anthony Giddens: Making sense of modernity. Stanford, CA: Stanford University Press.

18. Giddens, Anthony. (1973): The Class Structure of the Advanced Societies. London:

19. Goffman, Erving. (1959): The Presentation of Self in Everyday Life, revised edition. Garden City: Doubleday

20. Harriss, John. (2003): "The Great Tradition Globalizes: Reflections on Two Studies of the "Industrial Leaders" of Madras.' Modern Asian Studies 37: 327-62.

21. Jeffrey, C. (2010): Timepass: Youth, class, and time among unemployed young men in India. American Ethnologist, 37(3), 465-481.

22. Jeffrey, C., \& McDowell, L. (2004): Youth in a Comparative Perspective Global Change, Local Lives. Youth \& Society, 36(2), 131-142 
23. Kharas, H., \& Gertz, G. (2010): The new global middle class: A cross-over from West to East. Wolfensohn Center for Development at Brookings, 1-14.

24. Lakha, Salim. (1999): 'The State, Globalisation and Indian Middle-class Identity.' In Culture and Privilege in Capitalist Asia, Michael Pinches, ed., 251-74. London: Routledge.

25. Liechty, Mark. (2002): Suitably Modern: Making Middle-class Culture in a New Consumer Society. Princeton: Princeton University Press.

26. Lobo, L., \& Shah, J. (2014): The trajectory of India's middle class economy, ethics and etiquette. Newcastle upon Tyne, England: Cambridge Scholars Publishing.

27. Maitra, S. (2008): Who are the Indian Middle Class? A Mixture Model of Class Membership Based on Durables Ownership.

28. Meyer, Michael J. (2002): 'Dignity as a (Modern) Virtue.' In The Concept of Human Dignity in Human Rights Discourse, edited by David Kretzmer and Eckart Klein, 195-208.The Hague: Kluwer Law International.

29. Mines, Diane P. (2005): Fierce Gods: Inequality, Ritual, and the Politics of Dignity in a South Indian Village. Bloomington: Indiana University Press.

30. Offer, Avner. (2006): The Challenge of Affluence: Self--Control and Well--Being in the United States and Britain since 1950. Oxford: Oxford University Press.

31. Osella, Fillipo/ OSELLA, Caroline (2000): Social Mobility in Kerala. Modernity and Identity in Conflict. London et al.: Pluto Press.

32. Pinches, M. (1999): Entrepreneurship, consumption, ethnicity and national identity in the making of the Philippines' new rich. In Ibid. (Ed.), Culture and Privilege In Capitalist Asia, (pp. 275-301). London: Routledge.

33. Reese, N. (2008): We are Living in a Different Time Zone" Transnational Working Places and the Concept of a" Glocalized Intermediary Class.Austrian Journal of South-East Asian Studies, 1(2), 34-58.

34. Robison, Richard \& Goodman, David S. G., eds. (1996): The New Rich in Asia: Mobile Phones, McDonald's and Middle-class Revolution. London: Routledge.

35. Sarkar, S. (2008): The New Middle Class, Technology and Modernity in Seelampur. NCDG Working Paper No. 08-001. University of Massachusetts. Retrieved from:<<http://scholarworks.umass.edu/cgi/viewcontent.cgi?article=1029andcontext=n cdg > [Accessed 5 July 2009].

36. Sayer, Andrew. (2005): 'Class, Moral Worth and Recognition.' Sociology 39 (5): 947-63. On gaining recognition as middle class in Madurai / 243 Contributions to Indian Sociology 47, 2 (2013): 217-243

37. Schaber, Peter. (2011): 'Absolute Poverty: Human Dignity, Self--Respect, and Dependency.' In Humiliation, Degradation, Dehumanization, edited by Paulus Kaufmann, Hannes Kuch, Christian Neuhäeuser and Elaine Webster, 151-58. New York: Springer.

38. Sklair, L. (1995): Sociology of the Global System. London: Prentice Hall.

39. Turner, J. H. (1991): The structure of sociological theory. Belmont, CA: Wadsworth Publishing Company.

40. Upadhya, Carol. (2004): 'A New Transnational Capitalist Class? Capital Flows, Business Networks and Entrepreneurs in the Indian Software Industry.' Economic and Political Weekly 39 (48), 27 November 2004, 5141-51.

41. Varma, Pavan K. (1998): The Great Indian Middle Class. New Delhi: Penguin.

42. Vogel, Ezra F. (1971): Japan's New Middle Class: The Salary Man and His Family in a Tokyo Suburb (second edition). Berkeley: University of California Press. 